\title{
Risk factors and clinical outcomes of acute myeloid leukaemia with central nervous system involvement in adults
}

\author{
Chieh-Lung Cheng ${ }^{1}$, Chi-Cheng Li ${ }^{2}$, Hsin-An Hou' ${ }^{1}$ Wei-Quan Fang ${ }^{3}$, Chin-Hao Chang ${ }^{4}$, Chien-Ting Lin², \\ Jih-Luh Tang ${ }^{1}$, Wen-Chien Chou ${ }^{1,5}$, Chien-Yuan Chen ${ }^{1}$, Ming Yao ${ }^{1}$, Shang-Yi Huang ${ }^{1}$, Bor-Sheng Ko ${ }^{1}$, Shang-Ju Wu ${ }^{1}$, \\ Woei Tsay ${ }^{1}$ and Hwei-Fang Tien ${ }^{1 *}$
}

\begin{abstract}
Background: Acute myeloid leukaemia (AML) with central nervous system (CNS) involvement in adults is uncommon, and studies of this subject are scant.

Methods: We conducted a retrospective study to investigate the clinical aspects, cytogenetic abnormalities, molecular gene mutations and outcomes of adult AML patients with CNS involvement. Three hundred and ninety-five patients with newly diagnosed AML were reviewed.

Results: Twenty (5.1\%) patients had CNS involvement, including 7 (1.8\%) with initial CNS disease and 4 (1\%) who suffered an isolated CNS relapse. The patients with CNS involvement were younger, had higher leukocyte, platelet, and peripheral blast cell counts, FAB M4 morphology, and chromosome translocations involving 11q23 (11q23 abnormalities) more frequently than did the patients without CNS involvement. No differences in sex, haemoglobin levels, serum LDH levels, immunophenotype of leukaemia cells, or molecular gene mutations were observed between the two groups. Multivariate analyses showed that age $\leq 45$ years $(\mathrm{OR}, 5.933 ; 95 \% \mathrm{Cl}, 1.82$ to 19.343), leukocyte counts $\geq 50,000 / \mu \mathrm{l}(\mathrm{OR}$, $3.136 ; 95 \% \mathrm{Cl}, 1.083$ to 9.078$)$, and the presence of $11 \mathrm{q} 23$ abnormalities (OR, 5.548; $95 \% \mathrm{Cl}, 1.208$ to 25.489 ) were significant predictors of CNS involvement. Patients with initial CNS disease had 5-year overall survival and relapse-free survival rates that were similar to those without initial CNS disease. However, three of four patients who suffered an isolated CNS relapse died, and their prognosis was as poor as that of patients who suffered a bone marrow relapse.
\end{abstract}

Conclusion: CNS involvement in adult patients with AML is rare. Three significant risk factors for CNS involvement including age $\leq 45$ years, leukocyte counts $\geq 50,000 / \mu l$ and the presence of 11q23 abnormalities were identified in this study. Future investigations to determine whether adult AML patients having these specific risk factors would benefit from CNS prophylactic therapy are necessary.

Keywords: Adult, Acute myeloid leukaemia, Central nervous system, Prognosis, Risk factors

\section{Background}

Central nervous system (CNS) involvement in adults with acute myeloid leukaemia (AML) is uncommon, and its incidence is far less than that in patients with acute lymphoblastic leukaemia [1,2]. Most descriptions of the clinical features of AML with CNS involvement are from

\footnotetext{
* Correspondence: hftien@ntu.edu.tw

'Division of Hematology, Department of Internal Medicine, National Taiwan University Hospital, College of Medicine, National Taiwan University, No. 7, Chung-Shan South Road, Taipei 100, Taiwan

Full list of author information is available at the end of the article
}

studies of paediatric AML patients [3-6]. The incidence of CNS involvement in childhood AML ranges from 6\% to $29 \%$ [5-9]. Previous studies have shown that age < 2 years, high white blood cell (WBC) and peripheral blast cell (PBC) counts at diagnosis, French-AmericanBritish (FAB) M4 and M5 morphology, inversion of chromosome 16, and a hyperdiploid cytogenetic profile are risk factors for CNS involvement in paediatric AML patients at diagnosis [6-8]. On the other hand, isolated CNS relapse in paediatric patients with AML is associated with age $<2$ years, high WBC count, hepatosplenomegaly,

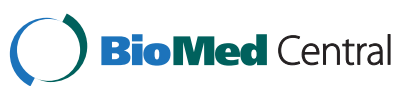

(C) 2015 Cheng et al.; licensee BioMed Central. This is an Open Access article distributed under the terms of the Creative Commons Attribution License (http://creativecommons.org/licenses/by/4.0), which permits unrestricted use, distribution, and reproduction in any medium, provided the original work is properly credited. The Creative Commons Public Domain Dedication waiver (http://creativecommons.org/publicdomain/zero/1.0/) applies to the data made available in this article, unless otherwise stated. 
CNS involvement at diagnosis, FAB M5 morphology, and chromosome 11q abnormalities [10]. Reports of the outcomes of paediatric AML patients with CNS involvement have varied. Certain studies have shown that CNS involvement confers a poor prognosis, [11,12] whereas others have shown that it exerts no effect on survival $[5,7,8,10]$.

The clinical features and treatment outcomes of adult AML patients with CNS involvement have not been well characterised. Peterson et al [13] described adult patients with acute nonlymphocytic leukaemia with CNS involvement, but their sample size was relatively small. Shihadeh et al [14] examined the cytogenetic profiles of AML patients with CNS disease in a cohort of 1354 patients in the United States, but did not examine the clinical outcomes. Rozovski et al [15] used the same cohort as Shihadeh et al and found that high serum levels of lactate dehydrogenase (LDH) at diagnosis, African-American ethnicity, and young age were risk factors for CNS involvement. Patients who achieved complete remission (CR) after induction chemotherapy had shorter diseasefree survival and overall survival (OS) if they had CNS involvement. Bar et al [16] reported risk factors and outcomes for CNS AML involvement in patients at the pre-haematopoietic stem cell transplantation (HSCT) evaluation. Covariates associated with CNS involvement were higher WBC counts at diagnosis, prior CNS or other extramedullary disease, and disease status at pre-HSCT evaluation. Presence of CNS involvement at pre-HSCT evaluation had no impact on post-HSCT outcome. However, participants in their study were limited to those who had undergone HSCT, which may have confounded their findings. In this study, we investigated the clinical characteristics and outcomes of a large cohort of adult AML patients in Taiwan to determine the risk factors and outcomes associated with CNS involvement in AML. Several characteristics which had not been included in previous studies, such as the immunophenotype of leukaemia cells and 13 relevant molecular gene mutations in AML, were also examined. In addition, we investigated the impact of CNS involvement on outcomes including separate analyses on those with initial CNS disease and those with isolated CNS relapse.

\section{Methods}

\section{Participants}

Our study was approved by the Institutional Review Board of National Taiwan University Hospital (NTUH), and was performed in accordance with the Declaration of Helsinki. All participants provided signed, informed consent before participation in our study. Patients aged $\geq$ 18 years who were newly diagnosed with AML at NTUH between January 2000 and December 2008 were reviewed for enrollment. The diagnosis and classification of AML were made according to the criteria of the FAB
Cooperative Group by the patient's primary care haematologist, an expert in FAB classification. Patients with acute promyelocytic leukaemia (FAB M3 subtype), antecedent haematological diseases or therapy-related AML were excluded from our study.

A total of 395 AML patients were included in our study, amongst whom 280 (70.9\%) received standard induction chemotherapy (idarubicin $12 \mathrm{mg} / \mathrm{m}^{2}$ per day for three days and cytarabine $100 \mathrm{mg} / \mathrm{m}^{2}$ per day for seven days) and then consolidation chemotherapy with three to four courses of high-dose cytarabine $\left(2000 \mathrm{mg} / \mathrm{m}^{2}\right.$ every 12 hours for four days, total eight doses), with or without an anthracycline (idarubicin or mitoxantrone), after achieving CR [17]. The remaining 115 patients received palliative therapy with supportive care and/or low-dose chemotherapy because of underlying comorbidity or the patient's request. Allogeneic HSCT was performed in 97 patients. Our treatment protocols did not routinely include CSF tested at diagnosis or CNS prophylactic therapy, such as intrathecal chemotherapy. Lumbar puncture was performed only if clinically indicated. Intrathecal chemotherapy in combination with systemic chemotherapy, including high dose cytarabine, was adopted as the CNS-directed treatment for patients with CNS involvement. Patients who failed to respond completely to intrathecal or systemic chemotherapy, and those who had CNS granulocytic sarcoma and/or cranial nerve impairment, received radiation therapy. The median dose of radiation given to patients was 24 grays (Gy) (range, 20 to $25 \mathrm{~Gy}$ ).

\section{Data collection}

We retrospectively reviewed the clinical characteristics, cytogenetic profiles, molecular gene mutations and outcomes of patients in our AML cohort. A diagnosis of CNS involvement required the confirmation of leukaemic blast cells in the centrifuged cerebrospinal fluid (CSF) with the presence of more than five WBCs in the CSF $[10,18]$ by at least two haematologists or the detection of a CNS granulocytic sarcoma using computed tomography or magnetic resonance imaging. Two clinical disease entities, initial CNS disease and isolated CNS relapse, were defined. Initial CNS disease consisted of the following conditions: (1) CNS involvement on the date of the initial AML diagnosis or (2) CNS involvement after receiving standard induction therapy and the absence of blast cells in the peripheral blood. Isolated CNS relapse was defined as a CNS relapse that was the first event following $C R$ without evidence of bone marrow $(\mathrm{BM})$ or other extramedullary relapse within 30 days [10]. The age, sex, FAB morphology subtype, haemogram, PBC, serum LDH level, immunophenotype of leukaemia cells, cytogenetics and molecular gene mutation at diagnosis of patients with CNS involvement were 
compared with those of patients without CNS involvement. Follow-up data were collected until death, loss to follow-up, or the end of the study period, June 30, 2011.

\section{Immunophenotyping}

Monoclonal antibodies to the myeloid-associated antigens CD13, CD33, CD11b, CD15, and CD14, the lymphoidassociated antigens CD2, CD5, CD7, CD19, CD10, and CD20, and the lineage-nonspecific antigens HLA-DR, CD34, and CD56 were used to characterise the immunophenotype of the leukaemia cells as previously described [19].

\section{Cytogenetics}

The BM cells were collected from AML patients for immediate cytogenetic analysis, or they were cultured for 1 to 3 days without exogenous stimulation before cytogenetic analysis as described previously [20]. The metaphase cells were banded using the trypsin-Giemsa technique, and karyotyped according to the International System for Human Cytogenetic Nomenclature (ISCN 2009) [21].

\section{Mutation analysis}

Mutation analysis of 13 relevant molecular marker genes, including NPM1, [22] CEBPA, [23] FLT3-internal tandem duplication, [24] RAS, [25] KIT, [26] MLL-partial tandem duplication, [27] WT1, [28] AML1/RUNX1, [29] ASXL1, [30] IDH1, [31] IDH2, [32] TET2, [33] and DNMT3A [34] was performed as previously reported. Abnormal sequencing results were confirmed by at least two repeated analyses.

\section{Statistical analysis}

The categorical data for patients with CNS involvement were compared with those of patients without CNS involvement, using a chi-squared analysis or the Fisher exact test. The Mann-Whitney $U$ test was used to compare the medians of the continuous variables. The univariate and multivariate logistic regression analyses were used to identify factors predictive of CNS involvement. Variables that met a significance level of $<0.2$ in the univariate analysis were included in the multivariate logistic regression analysis. The odds ratio (OR) from this analysis was used as a measure of the relative risk. OS was measured from the date of the first diagnosis to the end of the follow-up period, death from any cause, or the date of the last known follow-up examination. Relapse was defined as a reappearance of $\geq 5 \%$ leukaemic blast cells in a BM aspirate or newly developed extramedullary leukaemia in patients with a previously documented CR [35]. Relapse-free survival (RFS) was measured from the date of attaining a leukaemia-free state until the end of the follow-up period, the date of AML relapse, death from any cause, or the last known follow-up examination, whichever came first [35]. The Kaplan-Meier method was used to estimate the OS and the RFS, and the log-rank test was used to examine the significance of differences between the two groups. A two-sided $P$ value $<.05$ was considered to indicate a statistically significant difference. The entire cohort was included the analyses of the correlation between CNS involvement and the clinical characteristics. All patients with CNS involvement received standard induction chemotherapy. Those in the palliative group received heterogeneous treatment strategies. Hence only the patients who received conventional standard chemotherapy were included in the analysis of survival. All statistical analyses were performed using the SPSS, Version 17, computer software (IBM, Armonk, NY, USA).

\section{Results}

\section{Characteristics of the patients}

Of the 395 AML patients included in our study, 20 (5.1\%) developed CNS involvement, amongst whom seven (1.8\%) had initial CNS disease and four (1\%) suffered an isolated CNS relapse. Six patients (1.5\%) suffered a CNS relapse concurrent with or subsequent to a marrow relapse, and three patients $(0.8 \%)$ were diagnosed with primary refractory disease with subsequent CNS involvement. The clinical and laboratory data of patients with or without CNS involvement are shown in Table 1. Patients with CNS involvement had a lower median age (37.5 vs $54 \mathrm{y}, P<.001)$, and exhibited higher $\mathrm{WBC}, \mathrm{PBC}$, and platelet counts at diagnosis than those of patients without CNS involvement. In addition, patients with CNS involvement exhibited FAB-M4-subtype morphology more frequently $(P=.02)$ than did patients without CNS involvement. No differences in sex, haemoglobin levels, serum LDH levels, or the immunophenotype of leukaemia cells (Additional file 1: Table S1) were observed between the two groups.

\section{Correlation of CNS involvement with cytogenetics and molecular gene mutations}

Cytogenetic data were available for 378 patients at diagnosis. The karyotype characteristics of the AML patients are shown in Table 2. Patients with CNS involvement had a significantly higher incidence of the chromosome translocations involving 11q23 (11q23 abnormalities) $(21.1 \%$ vs $2.8 \%, P=.003)$ than did those without CNS involvement. Data on molecular gene mutations of the AML patients are shown in Additional file 1: Table S2. The molecular gene mutations observed in the two groups did not differ.

\section{Risk factors associated with CNS involvement}

In multivariate logistic regression analysis including variables significantly associated with CNS involvement in univariate analysis (Table 3), the independent risk factors 
Table 1 Comparison of clinical and laboratory characteristics of patients with and without CNS involvement

\begin{tabular}{|c|c|c|c|c|}
\hline Variables & Total $(n=395)$ & $\begin{array}{l}\text { Patients with CNS } \\
\text { involvement }(n=20)\end{array}$ & $\begin{array}{l}\text { Patients without CNS } \\
\text { involvement }(n=375)\end{array}$ & $P$ value \\
\hline Sex $\dagger$ & & & & 0.648 \\
\hline Male & 220 & $10(50)$ & $210(56)$ & \\
\hline Female & 175 & $10(50)$ & $165(44)$ & \\
\hline Age (year) $\ddagger$ & $53(18-90)$ & $37.5(21-72)$ & $54(18-90)$ & $<0.001$ \\
\hline \multicolumn{5}{|l|}{ Laboratory data $\neq$} \\
\hline 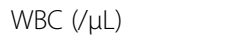 & 21950(120-423000) & $83865(1860-277250)$ & $21050(120-423000)$ & 0.003 \\
\hline Haemoglobin (g/dL) & $8.1(2.9-14.5)$ & $8.1(4.9-14.5)$ & $8.1(2.9-14)$ & 0.392 \\
\hline Platelet $(\times 1,000 / \mu \mathrm{L})$ & $45(1-802)$ & $71.5(11-255)$ & $44(1-802)$ & 0.03 \\
\hline $\mathrm{PBC}(/ \mu \mathrm{L})$ & $9014(0-369070)$ & $42751(0-260615)$ & $8360(0-369070)$ & 0.009 \\
\hline $\mathrm{LDH}(\mathrm{U} / \mathrm{L})$ & 859(206-13130) & $1641.5(265-8693)$ & 842(206-13130) & 0.069 \\
\hline \multicolumn{5}{|l|}{$\mathrm{FAB}+$} \\
\hline Mo & 11 & $0(0)$ & $11(2.9)$ & $>0.999$ \\
\hline M1 & 85 & $4(20)$ & $81(21.6)$ & $>0.999$ \\
\hline M2 & 139 & $3(15)$ & 136(36.3) & 0.057 \\
\hline M4 & 116 & $11(55)$ & $105(28)$ & 0.02 \\
\hline M5 & 20 & $1(5)$ & 19(5.1) & $>0.999$ \\
\hline M6 & 15 & $0(0)$ & $15(4)$ & $>0.999$ \\
\hline Undetermined & 9 & $1(5)$ & $8(2.1)$ & 0.377 \\
\hline
\end{tabular}

tnumber of patients (\%).

łmedian (range).

Abbreviation: CNS central nervous system, WBC white blood cell, $P B C$ peripheral blast cell, $L D H$ lactate dehydrogenase, $F A B$ French-American-British.

Table 2 Comparison of chromosomal abnormalities* seen in patients with and without CNS involvement

\begin{tabular}{|c|c|c|c|c|}
\hline \multirow[t]{2}{*}{ Variables } & \multirow[t]{2}{*}{ Total $(n=378)$} & Patients with CNS involvement $(n=19)$ & Patients without CNS involvement $(n=359)$ & $P$ value \\
\hline & & \multicolumn{3}{|l|}{ Number (\%) of patients } \\
\hline Karyotype $^{\dagger}$ & & & & 0.378 \\
\hline Favorable & 50 & $3(15.8)$ & $47(13.1)$ & \\
\hline Intermediate & 264 & 15(78.9) & 249(69.4) & \\
\hline Unfavorable & 64 & $1(5.3)$ & $63(17.5)$ & \\
\hline $\mathrm{t}(8 ; 21)$ & 34 & $1(5.3)$ & $33(9.2)$ & $>0.999$ \\
\hline $\operatorname{inv}(16)$ & 16 & $2(10.5)$ & $14(3.9)$ & 0.189 \\
\hline $11 \mathrm{q} 23$ abnormalities & 14 & $4(21.1)$ & $10(2.8)$ & 0.003 \\
\hline$-5 / 5 q^{-} \neq$ & 1 & $0(0)$ & $1(0.3)$ & $>0.999$ \\
\hline$-7 / 7 q^{-}{ }^{\neq}$ & 6 & $0(0)$ & $6(1.7)$ & $>0.999$ \\
\hline$t(7 ; 11)$ & 4 & $0(0)$ & $4(1.1)$ & $>0.999$ \\
\hline $\mathrm{t}(6 ; 9)$ & 2 & $0(0)$ & $2(0.6)$ & $>0.999$ \\
\hline$+8^{\ddagger}$ & 17 & $1(5.3)$ & $16(4.5)$ & 0.592 \\
\hline
\end{tabular}

*Three hundred and seventy-eight patients had cytogenetic profiles at diagnosis. The remaining 17 patients did not have data of cytogenetic profiles because of inadequate metaphase cells for alalysis.

${ }^{\dagger}$ Favorable, $\mathrm{t}(8 ; 21)$, inv (16); unfavorable, -7 , del(7q), -5 , del(5q), 3q abnormality, complex abnormalities; Intermediate, normal karyotype and other abnormalities. ${ }^{\ddagger}$ Includes only simple chromosomal abnormalities with 2 or fewer changes, but not those with complex abnormalities with 3 or more aberrations.

Abbreviation: CNS central nervous system. 
Table 3 Univariate and multivariate analyses to identify the risk factors predictive of CNS involvement

\begin{tabular}{|c|c|c|c|c|c|c|}
\hline \multirow[t]{2}{*}{ Variable } & \multicolumn{3}{|c|}{ Univariate analysis } & \multicolumn{3}{|c|}{ Multivariate analysis } \\
\hline & OR & $95 \% \mathrm{Cl}$ & $P$ value & OR & $95 \% \mathrm{Cl}$ & $P$ value \\
\hline $\mathrm{Age}^{*}$ & 5.654 & $2.01-15.904$ & 0.001 & 5.933 & $1.82-19.343$ & 0.003 \\
\hline Sex & 0.786 & $0.319-1.932$ & 0.599 & - & - & - \\
\hline WBC† & 4.069 & $1.616-10.244$ & 0.003 & 3.136 & $1.083-9.078$ & 0.035 \\
\hline Platelet§ & 2.303 & $0.755-7.026$ & 0.143 & 2.804 & $0.799-9.837$ & 0.107 \\
\hline $\mathrm{LDH} \neq$ & 1.931 & $0.688-5.425$ & 0.212 & - & - & - \\
\hline FAB M4ף & 3.143 & $1.266-7.803$ & 0.014 & 2.023 & $0.646-6.341$ & 0.227 \\
\hline $\operatorname{inv}(16)^{\Delta}$ & 2.899 & $0.609-13.79$ & 0.181 & 1.176 & $0.277-10.612$ & 0.562 \\
\hline 11q23 abnormalities" & 9.307 & $2.615-33.123$ & 0.001 & 5.548 & $1.208-25.489$ & 0.028 \\
\hline
\end{tabular}

Only variables with $P$ value $<0.2$ in the univariate analysis were incorporated into the multivariate logistic regression analysis.

${ }^{*}$ Age $\leq 45$ y relative to age $>45 \mathrm{y}$.

tWBC greater than or equal to $50,000 / \mu \mathrm{L}$ vs less than $50,000 / \mu \mathrm{L}$.

§Platelet greater than or equal to $30,000 / \mu \mathrm{L}$ vs less than $30,000 / \mu \mathrm{L}$.

$\neq \mathrm{LDH}$ greater than or equal to two times the upper limit of normal vs less than two times the upper limit of normal.

IFrench-American-British M4 morphology vs others.

$\triangle$ Inversion of chromosome 16 vs others.

"chromosome translocations involving $11 \mathrm{q} 23$ vs others.

Abbreviation: CNS, central nervous system; OR, odds ratio; Cl, confidence interval; WBC, white blood cell; LDH, lactate dehydrogenase.

were age $\leq 45$ years (OR, 5.933; 95\% CI, 1.82 to 19.343), WBC counts $\geq 50,000 / \mu \mathrm{L}$ (OR, 3.136; 95\% CI, 1.083 to 9.078), and the presence of 11q23 abnormalities (OR, 5.548; $95 \%$ CI, 1.208 to 25.489 ).

\section{Clinical characteristics and outcomes of patients with initial CNS disease}

The clinical features and treatment outcomes of the patients with initial CNS disease $(n=7)$ are summarized in Table 4. Patients with initial CNS disease had higher WBC counts at diagnosis $(P=.041)$ than those without initial CNS disease. Furthermore, the incidence of the chromosome 16 inversion was significantly higher $(P=.001)$ in patients who had initial CNS disease than in patients without initial CNS disease.

The CR rates and primary refractory rates amongst patients with initial CNS disease were similar to those of patients without initial CNS disease (Additional file 1: Table S3). The median follow-up interval was 58.1 months (range: 0.1-139.3). The 5-year OS and RFS rates of the patients with initial CNS disease were not significantly different to those of the patients without initial CNS disease $(P=.252$ and $P=.123$, respectively, Figure 1$)$.

\section{Clinical characteristics and outcomes of patients with isolated CNS relapse}

The clinical characteristics and treatment outcomes of the four AML patients who suffered an isolated CNS relapse are listed in Table 5. None of these patients had initial CNS disease. The median interval from attaining CR status to the first detection of isolated CNS relapse was 3.2 months. The patients who suffered an isolated CNS relapse were younger, had higher WBC counts and were more likely to have FAB-M4-subtype morphology than the patients without an isolated CNS relapse $(P=.008, P=.022$, and $P=0.044$, respectively). The $11 \mathrm{q} 23$ abnormalities were more prevalent amongst patients who suffered an isolated CNS relapse than in patients without CNS relapse $(P<.001)$. Three of four patients who suffered an isolated CNS relapse developed a

Table 4 Clinical characteristics and treatment outcomes of patients with initial CNS disease

\begin{tabular}{|c|c|c|c|c|c|c|c|c|c|}
\hline Patient & Age (years) & Gender & FAB & Leukocyte $(/ \mu \mathrm{L})$ & Cytogenetics & CNS Symptoms & Relapse & HSCT & Outcome \\
\hline 1 & 43 & $F$ & M1 & 1860 & $\mathrm{CN}$ & Seizure & Yes $^{\#}$ & Yes & $C R$ in $52.7 \mathrm{~m}$ \\
\hline 2 & 21 & $\mathrm{~F}$ & $\mathrm{M} 2$ & 15430 & $t(8 ; 21)$ & Blurred vision & No & Yes & $C R$ in $41.4 \mathrm{~m}$ \\
\hline 3 & 60 & $\mathrm{~F}$ & M4 & 74390 & $\mathrm{t}(9 ; 11)(\mathrm{p} 22 ; \mathrm{q} 23)$ & Dizziness & $-\Delta$ & No & Died in $3 \mathrm{~m}$ \\
\hline 4 & 26 & $\mathrm{~F}$ & M4 & 175900 & $\operatorname{inv}(16)$ & Headache & No & No & CR in $63.1 \mathrm{~m}$ \\
\hline 5 & 72 & M & M4 & 168630 & $\operatorname{inv}(16)$ & Dizziness & No & No & CR in $40.9 \mathrm{~m}$ \\
\hline 6 & 53 & $\mathrm{~F}$ & M4 & 93340 & +8 & Paresthesias & No & No & Died in $4.3 \mathrm{~m}$ \\
\hline 7 & 40 & M & M1 & 277250 & $\mathrm{CN}$ & Headache & No & No & CR in $58.1 \mathrm{~m}$ \\
\hline
\end{tabular}

"This patient suffered from marrow relapse but not CNS relapse.

${ }^{\Delta}$ This patient suffered from induction death after standard induction chemotherapy.

Abbreviation: $F$, female; $M$, male; $F A B$, French-American-British; CN, normal karyotype; CNS, central nervous system; HSCT, hematopoietic, stem cell transplantation; $\mathrm{CR}$, complete remission; $\mathrm{m}$, month. 


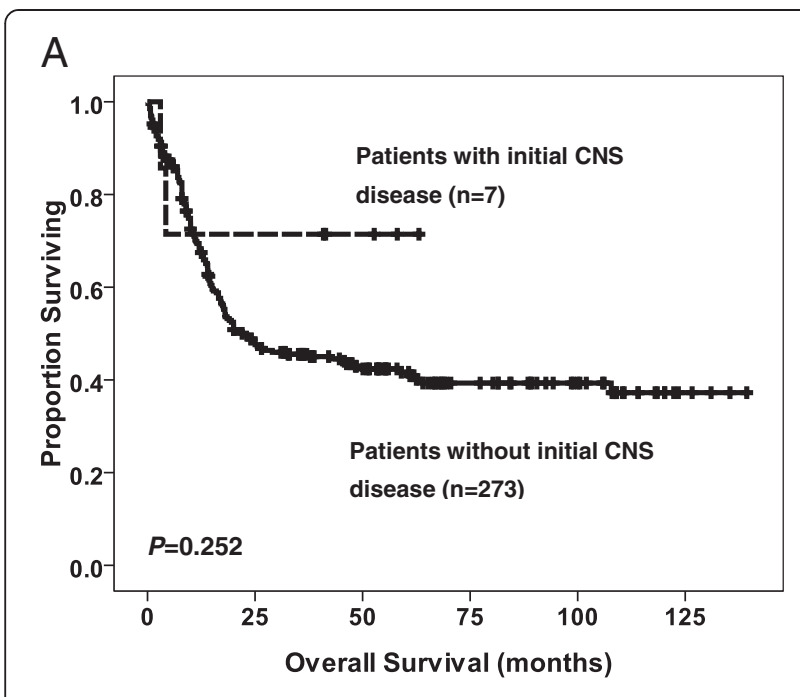

B

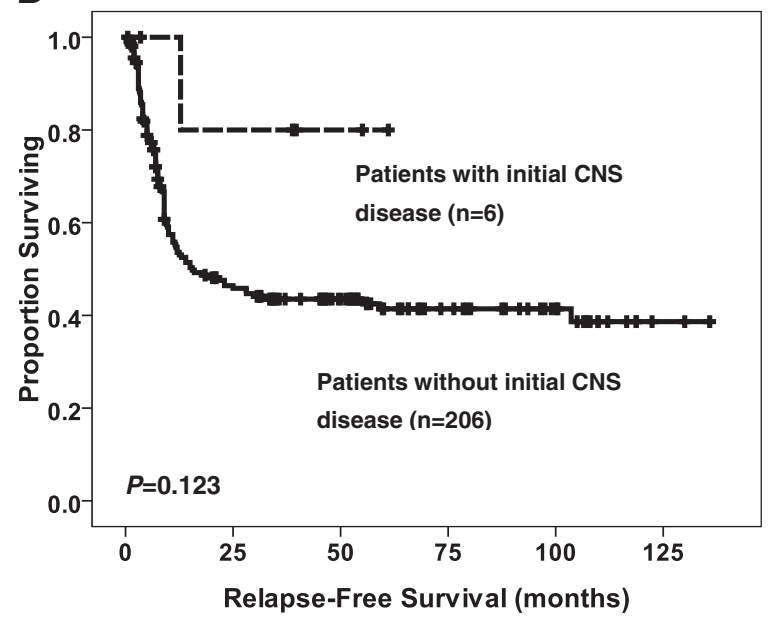

Figure 1 Kaplan-Meier curves for overall survival (A) and relapse-free survival (B) of AML patients $\geq 18$ years of age stratified based their status of CNS involvement at diagnosis. Only those receiving conventional standard chemotherapy were included in the survival analyses.

subsequent $\mathrm{BM}$ relapse and died. The OS rate following an isolated CNS relapse was as poor as that following a $\mathrm{BM}$ relapse, with a median interval from isolated CNS relapse to death of 8.5 months (Figure 2).

\section{Discussion}

Our current study examined the rate of CNS involvement in a large cohort of adult AML patients. The incidence of CNS involvement amongst adult AML patients at our institution was $5.1 \%$. This result is similar to that reported in other studies, that the incidence of CNS involvement concurrent with or subsequent to AML diagnosis in adults is uncommon [1,15,36]. The AML patients with CNS involvement were younger, exhibited higher WBC, platelet, and peripheral blood blast cell counts, and had FAB M4 morphology, and 11q23 abnormalities more frequently than did the AML patients without CNS involvement. By multivariate analysis, the risk factors significantly associated with CNS involvement included age $\leq 45$ years, WBC counts $\geq 50,000 / \mu \mathrm{L}$, and the presence of $11 \mathrm{q} 23$ abnormalities. No significant difference in 5-year OS and RFS rates was observed between the AML patients with initial CNS disease and those without it. In contrast, the prognosis of patients who suffered an isolated CNS relapse was as poor as that of patients who suffered a bone marrow relapse.

Young age has previously been considered as a risk factor for CNS involvement and it was also observed in this study $[14,15,37]$. Since certain FAB subtypes, such as M4 AML, or cytogenetic abnormalities, such as the chromosome 16 inversion, are commoner in younger adults and are also more frequently associated with extramedullary infiltrates, this is likely to at least partly explain the association between CNS disease and younger age found in this and other studies. A large leukaemic cell burden, as represented by high WBC counts and high serum LDH levels, has been shown to be significantly associated with CNS involvement [3,8,13-16]. We observed that AML patients with high WBC counts at diagnosis had a significantly higher incidence of CNS involvement (Table 3). However, the association between serum LDH levels and CNS involvement was not statistically significant in our study $(P=0.069)$.

Chromosomal changes or molecular gene mutations in AML have clinical implications. Karyotype abnormalities, such as the chromosome 16 inversion, chromosome $11 \mathrm{q} 23$ abnormality, trisomy $8, \mathrm{t}(9 ; 11)$ translocation, and hyperdiploidism have been shown to be significantly associated with CNS involvement in paediatric AML $[7,8,10,14]$. We observed that the chromosome 16 inversion was more prevalent amongst patients with initial CNS disease, whereas the 11q23 abnormalities were more common amongst patients that suffered an isolated CNS relapse. These findings are consistent with those of previous studies of paediatric AML patients $[8,10]$. On the other hand, no relevant molecular gene mutation associated with CNS involvement was identified in this study.

Reports of outcome about CNS involvement in adults with AML are limited. Chang et al reported that extramedullary infiltrates were associated with poor outcome in adult patients with AML, but their investigation did not focus specifically on CNS involvement [38]. Mayadev et al [39] showed that CNS involvement was associated with poor prognosis in adult AML patients. On the contrary, other two studies $[16,37]$ showed that the outcomes for AML with CNS involvement were comparable with those for AML without CNS involvement. However, participant selection for these three studies was limited to patients who had undergone HSCT, which may have confounded 
Table 5 Clinical characteristics and treatment outcomes of patients with isolated CNS relapse

\begin{tabular}{|c|c|c|c|c|c|c|c|c|c|c|c|c|}
\hline Patient & $\begin{array}{l}\begin{array}{l}\text { Age } \\
\text { (years) }\end{array}\end{array}$ & Gender & FAB & $\begin{array}{l}\text { Leukocyte } \\
(/ \mu \mathrm{L})\end{array}$ & Cytogenetics & $\begin{array}{l}\text { Initial CNS } \\
\text { disease }\end{array}$ & CNS Symptoms & $\begin{array}{l}\text { Radiation } \\
\text { therapy* }\end{array}$ & HSCT & $\begin{array}{l}\text { Time from } \\
\text { remission to CNS } \\
\text { relapse (months) }\end{array}$ & $\begin{array}{l}\text { Time from CNS } \\
\text { relapse to BM } \\
\text { relapse (months) }\end{array}$ & $\begin{array}{l}\text { Outcome after } \\
\text { isolated CNS } \\
\text { relapse }\end{array}$ \\
\hline 1 & 24 & $M$ & M5 & 113510 & $\mathrm{t}(9 ; 11 ; 13)(p 22 ; q 23 ; q 34)$ & $\mathrm{Nil}$ & Headache & No & Yes & 2 & - & $C R$ in $41.6 \mathrm{~m}$ \\
\hline 2 & 28 & M & M4 & 172700 & $\mathrm{t}(11 ; 19)(q 23 ; p 13)$ & $\mathrm{Nil}$ & Tremor & Yes & No & 14 & 5.8 & Died in $7.4 \mathrm{~m}$ \\
\hline 3 & 28 & $\mathrm{~F}$ & M4 & 123550 & $\mathrm{t}(6 ; 11)(\mathrm{q} 27 ; \mathrm{q} 23)$ & $\mathrm{Nil}$ & Dizziness & No & Yes & 3.3 & $14.9^{\#}$ & Died in $41.4 \mathrm{~m}$ \\
\hline 4 & 35 & M & M4 & 33510 & $\mathrm{CN}$ & $\mathrm{Nil}$ & Blurred vision & Yes & Yes & 3.2 & 2.3 & Died in $5.8 \mathrm{~m}$ \\
\hline
\end{tabular}

*All patients received intensive systemic chemotherapy and intrathecal chemotherapy.

"Bone marrow relapses of this patient happened after hematopoietic stem cell transplantation

Abbreviation: $F$ female, $M$ male, FAB French-American-British, CN normal karyotype, CNS central nervous system, HSCT hematopoietic stem cell transplantation, BM bone marrow, $C R$ complete remission, $m$ month. 


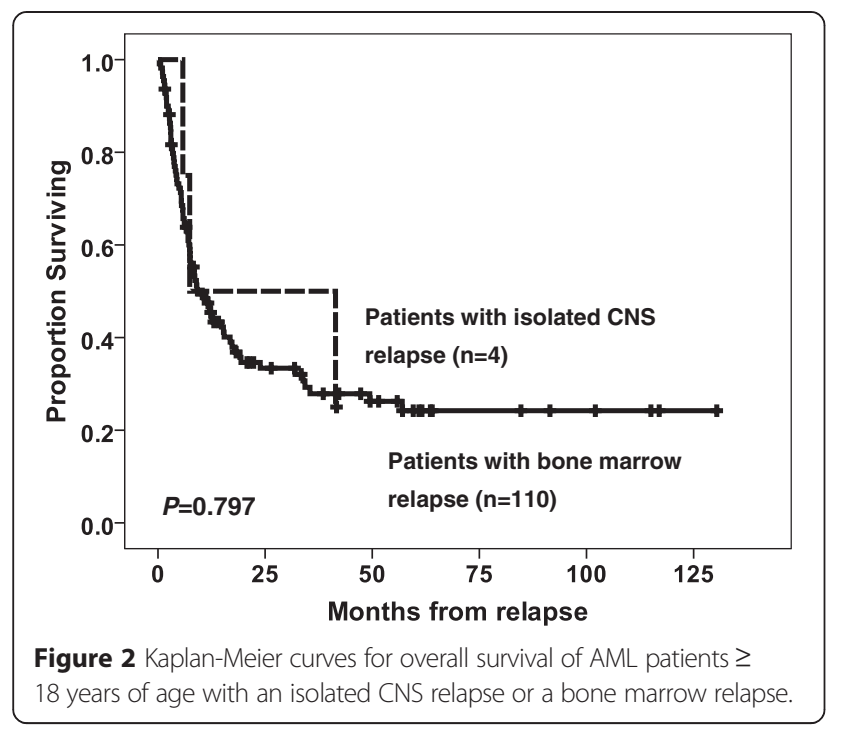

their results. In our study, the 5-year OS and RFS of patients with initial CNS disease were similar to those of AML patients without CNS disease. These findings may be partially explained by the higher frequency of favorable cytogenetics (inversion of chromosome 16), the absence of CNS relapse, and low rate of BM relapse (16.7\%, Table 4) amongst the patients with initial CNS disease. By contrast, our data demonstrated that the outcome of patients who suffered an isolated CNS relapse was actually poor. Three of four patients $(75 \%)$ who suffered an isolated CNS relapse developed a subsequent BM relapse and died, despite receiving cranial irradiation or allogeneic HSCT.

No consensus exists regarding the treatment of AML patients with CNS involvement. The preference of treatment protocols used in our study is largely based on the capacity of intrathecal chemotherapy to clear the leukaemic cells of CSF quickly in most patients and the efficacy of high doses of cytarabine for penetrating the CNS [40,41]. Moreover, the potential acute and long-term complications associated with cranial irradiation often limit its use. Aoki et al [37] reported that allogeneic HSCT may improve outcomes for CNS involvement in patients with AML. However, further prospective studies are necessary to clarify this point. Future investigations of more effective CNS-directed treatment strategies are warranted to improve the outcomes of such patients, particularly those who suffer an isolated CNS relapse.

The limitation of our study is that this is a single centre, retrospective study. Nevertheless, most published studies concerning this subject have also been retrospective. Identifying adult patients with AML who are at risk for CNS involvement will enable us to restrict the use of CNS prophylactic therapy to those who are most likely to benefit. In this study three significant risk factors for CNS involvement in adult patients with AML were recognized. Further studies with large cohorts are necessary to validate this point.

\section{Conclusions}

Our study of a large cohort of adult AML patients revealed that the incidence of $\mathrm{CNS}$ involvement is low. Age $\leq 45$ years, WBC counts $\geq 50,000 / \mu \mathrm{L}$ and the presence of 11q23 abnormalities are independent risk factors for adult AML patients with CNS involvement either at diagnosis or during the course of the disease. The OS rate is similar between patients with initial CNS disease and those without it. However, the prognosis of patients who suffer an isolated CNS relapse is as poor as that of patients who suffered a bone marrow relapse. Whether routine CNS prophylactic therapy should be given as part of conventional standard chemotherapy in adult AML patients having these specific risk factors needs to be further investigated.

\section{Additional file}

Additional file 1: Table S1. Comparison of immunophenotype of leukemia cells seen in patients with and without central nervous system involvement. Table S2. Comparison of molecular gene mutation* seen in patients with and without central nervous system involvement. Table S3. Comparison of treatment response of patients with and without initial CNS disease by standard remission induction therapy.

\section{Abbreviations}

CNS: Central nervous system; AML: Acute myeloid leukaemia; WBC: White blood cell; PBC: Peripheral blast cell; FAB: French-American-British;

NTUH: National Taiwan University Hospital; HSCT: Haematopoietic stem cell transplantation; CSF: Cerebrospinal fluid; CR: Complete remission; BM: Bone marrow; LDH: Lactate dehydrogenase; OR: Odds ratio; OS: Overall survival; RFS: Relapse-free survival.

\section{Competing interests}

The authors declare that they have no competing interests.

\section{Authors' contributions}

CLC had the original idea for the study, analysed and interpreted data, did statistical analyses, and wrote the manuscript. $\mathrm{CCL}$ and $\mathrm{H}-\mathrm{AH}$ helped to design the study and performed collection and assembly of data. W-QF and C-HC were responsible for statistical analyses. CTL, JLT, WCC, CYC, MY, SYH, BSK, SJW, and WT participated in data collection and provision of patients. HFT coordinated the study over the entire period and participated in editing and proofreading. All authors read and approved the final manuscript.

\section{Acknowledgements}

This work was partially sponsored by Grants NSC 97-2314-B002-015-MY3, NSC-97-2628-B-002-002-MY3, NSC 100-2325-B002-032 and NSC 100-2628-B002-003-MY3 from the National Science Council (Taiwan), DOH99-TD-C- 111001 from the Department of Health (Taiwan) and NTUH 99P14 and 100P07 from the Department of Medical Research, National Taiwan University Hospital.

\section{Author details}

${ }^{1}$ Division of Hematology, Department of Internal Medicine, National Taiwan University Hospital, College of Medicine, National Taiwan University, No. 7, Chung-Shan South Road, Taipei 100, Taiwan. ${ }^{2}$ Taicheng stem cell therapy center, National Taiwan University, Taipei, Taiwan. ${ }^{3}$ Taiwan Clinical Trial Bioinformatics and Statistical Center, Training Center, and Pharmacogenomics Laboratory, Taipei, Taiwan. ${ }^{4}$ Department of Medical Research, National Taiwan University Hospital, College of Medicine, National 
Taiwan University, Taipei, Taiwan. ${ }^{5}$ Department of Laboratory Medicine, National Taiwan University Hospital, College of Medicine, National Taiwan University, Taipei, Taiwan.

\section{Received: 18 August 2014 Accepted: 27 April 2015 Published online: 02 May 2015}

\section{References}

1. Stewart DJ, Keating MJ, McCredie KB, Smith TL, Youness E, Murphy SG, et al. Natural history of central nervous system acute leukemia in adults. Cancer. 1981;47(1):184-96

2. Wolk RW, Masse SR, Conklin R, Freireich EJ. The incidence of central nervous system leukemia in adults with acute leukemia. Cancer. 1974;33(3):863-9.

3. Pui CH, Dahl GV, Kalwinsky DK, Look AT, Mirro J, Dodge RK, et al. Central nervous system leukemia in children with acute nonlymphoblastic leukemia. Blood. 1985;66(5):1062-7.

4. Gibson BE, Wheatley K, Hann IM, Stevens RF, Webb D, Hills RK, et al. Treatment strategy and long-term results in paediatric patients treated in consecutive UK AML trials. Leukemia. 2005;19(12):2130-8.

5. Bisschop MM, Revesz T, Bierings M, van Weerden JF, van Wering ER, Hahlen $\mathrm{K}$, et al. Extramedullary infiltrates at diagnosis have no prognostic significance in children with acute myeloid leukaemia. Leukemia. 2001;15(1):46-9.

6. Webb DK, Harrison G, Stevens RF, Gibson BG, Hann IM, Wheatley K. Relationships between age at diagnosis, clinical features, and outcome of therapy in children treated in the medical research council AML 10 and 12 trials for acute myeloid leukemia. Blood. 2001;98(6):1714-20.

7. Abbott BL, Rubnitz JE, Tong X, Srivastava DK, Pui CH, Ribeiro RC, et al. Clinical significance of central nervous system involvement at diagnosis of pediatric acute myeloid leukemia: a single institution's experience. Leukemia. 2003;17(11):2090-6.

8. Johnston DL, Alonzo TA, Gerbing RB, Lange BJ, Woods WG. The presence of central nervous system disease at diagnosis in pediatric acute myeloid leukemia does not affect survival: a Children's Oncology Group study. Pediatr Blood Cancer. 2010;55(3):414-20.

9. Creutzig U, Zimmermann M, Ritter J, Reinhardt D, Hermann J, Henze G, et al. Treatment strategies and long-term results in paediatric patients treated in four consecutive AML-BFM trials. Leukemia. 2005;19(12):2030-42.

10. Johnston DL, Alonzo TA, Gerbing RB, Lange BJ, Woods WG. Risk factors and therapy for isolated central nervous system relapse of pediatric acute myeloid leukemia. J Clin Oncol. 2005;23(36):9172-8.

11. Kobayashi R, Tawa A, Hanada R, Horibe K, Tsuchida M, Tsukimoto I. Extramedullary infiltration at diagnosis and prognosis in children with acute myelogenous leukemia. Pediatr Blood Cancer. 2007:48(4):393-8.

12. Woods WG, Kobrinsky N, Buckley J, Neudorf S, Sanders J, Miller L, et al. Intensively timed induction therapy followed by autologous or allogeneic bone marrow transplantation for children with acute myeloid leukemia or myelodysplastic syndrome: a Childrens Cancer Group pilot study. J Clin Oncol. 1993;11(8):1448-57.

13. Peterson BA, Brunning RD, Bloomfield CD, Hurd DD, Gau JA, Peng GT, et al. Central nervous system involvement in acute nonlymphocytic leukemia. A prospective study of adults in remission. Am J Med. 1987;83(3):464-70.

14. Shihadeh F, Reed V, Faderl S, Medeiros LJ, Mazloom A, Hadziahmetovic M, et al. Cytogenetic profile of patients with acute myeloid leukemia and central nervous system disease. Cancer. 2012;118(1):112-7.

15. Rozovski U, Ohanian M, Ravandi F, Garcia-Manero G, Faderl S, Pierce S, et al. Incidence of and risk factors for involvement of the central nervous system in acute myeloid leukemia. Leuk Lymphoma. 2014;1:6.

16. Bar M, Tong W, Othus M, Loeb KR, Estey EH. Central nervous system involvement in acute myeloid leukemia patients undergoing hematopoietic cell transplantation. Biol Blood Marrow Transplant. 2015;21(3):546-51.

17. Cheng CL, Hou HA, Lee MC, Liu CY, Jhuang JY, Lai YJ, et al. Higher bone marrow LGALS3 expression is an independent unfavorable prognostic factor for overall survival in patients with acute myeloid leukemia. Blood. 2013;121(16):3172-80.

18. Woods WG, Kobrinsky N, Buckley JD, Lee JW, Sanders J, Neudorf S, et al. Timed-sequential induction therapy improves postremission outcome in acute myeloid leukemia: a report from the Children's cancer group. Blood. 1996:87(12):4979-89.

19. Chou WC, Tang JL, Lin LI, Yao M, Tsay W, Chen CY, et al. Nucleophosmin mutations in de novo acute myeloid leukemia: the age-dependent incidences and the stability during disease evolution. Cancer Res. 2006;66(6):3310-6.

20. Tien HF, Wang CH, Lin MT, Lee FY, Liu MC, Chuang SM, et al. Correlation of cytogenetic results with immunophenotype, genotype, clinical features, and ras mutation in acute myeloid leukemia. A study of 235 Chinese patients in Taiwan. Cancer Genet Cytogenet. 1995;84(1):60-8.

21. Brothman AR, Persons DL, Shaffer LG. Nomenclature evolution: changes in the ISCN from the 2005 to the 2009 edition. Cytogenet Genome Res. 2009;127(1):1-4.

22. Falini B, Mecucci C, Tiacci E, Alcalay M, Rosati R, Pasqualucci L, et al. Cytoplasmic nucleophosmin in acute myelogenous leukemia with a normal karyotype. N Engl J Med. 2005;352(3):254-66.

23. Lin LI, Chen CY, Lin DT, Tsay W, Tang JL, Yeh YC, et al. Characterization of CEBPA mutations in acute myeloid leukemia: most patients with CEBPA mutations have biallelic mutations and show a distinct immunophenotype of the leukemic cells. Clin Cancer Res. 2005;11(4):1372-9.

24. Chou WC, Hou HA, Liu CY, Chen CY, Lin LI, Huang YN, et al. Sensitive measurement of quantity dynamics of FLT3 internal tandem duplication at early time points provides prognostic information. Ann Oncol. 2011;22(3):696-704.

25. Chen CY, Lin LI, Tang JL, Tsay W, Chang HH, Yeh YC, et al. Acquisition of JAK2, PTPN11, and RAS mutations during disease progression in primary myelodysplastic syndrome. Leukemia. 2006;20(6):1155-8.

26. Chen CY, Lin LI, Tang JL, Ko BS, Tsay W, Chou WC, et al. RUNX1 gene mutation in primary myelodysplastic syndrome-the mutation can be detected early at diagnosis or acquired during disease progression and is associated with poor outcome. Br J Haematol. 2007;139(3):405-14.

27. Shiah HS, Kuo YY, Tang JL, Huang SY, Yao M, Tsay W, et al. Clinical and biological implications of partial tandem duplication of the MLL gene in acute myeloid leukemia without chromosomal abnormalities at 11q23. Leukemia. 2002;16(2):196-202.

28. Hou HA, Huang TC, Lin LI, Liu CY, Chen CY, Chou WC, et al. WT1 mutation in 470 adult patients with acute myeloid leukemia: stability during disease evolution and implication of its incorporation into a survival scoring system. Blood. 2010;115(25):5222-31.

29. Tang JL, Hou HA, Chen CY, Liu CY, Chou WC, Tseng MH, et al. AML1/RUNX1 mutations in 470 adult patients with de novo acute myeloid leukemia: prognostic implication and interaction with other gene alterations. Blood. 2009;114(26):5352-61.

30. Chou WC, Huang HH, Hou HA, Chen CY, Tang JL, Yao M, et al. Distinct clinical and biological features of de novo acute myeloid leukemia with additional sex comb-like 1 (ASXL1) mutations. Blood. 2010;116(20):4086-94.

31. Chou WC, Hou HA, Chen CY, Tang JL, Yao M, Tsay W, et al. Distinct clinical and biologic characteristics in adult acute myeloid leukemia bearing the isocitrate dehydrogenase 1 mutation. Blood. 2010;115(14):2749-54.

32. Chou WC, Lei WC, Ko BS, Hou HA, Chen CY, Tang JL, et al. The prognostic impact and stability of Isocitrate dehydrogenase 2 mutation in adult patients with acute myeloid leukemia. Leukemia. 2011;25(2):246-53.

33. Chou WC, Chou SC, Liu CY, Chen CY, Hou HA, Kuo YY, et al. TET2 mutation is an unfavorable prognostic factor in acute myeloid leukemia patients with intermediate-risk cytogenetics. Blood. 2011;118(14):3803-10.

34. Hou HA, Kuo YY, Liu CY, Chou WC, Lee MC, Chen CY, et al. DNMT3A mutations in acute myeloid leukemia: stability during disease evolution and clinical implications. Blood. 2012;119(2):559-68.

35. Cheson BD, Bennett JM, Kopecky KJ, Buchner T, Willman CL, Estey EH, et al. Revised recommendations of the international working group for diagnosis, standardization of response criteria, treatment outcomes, and reporting standards for therapeutic trials in acute myeloid leukemia. J Clin Oncol. 2003;21(24):4642-9.

36. Castagnola C, Nozza A, Corso A, Bernasconi C. The value of combination therapy in adult acute myeloid leukemia with central nervous system involvement. Haematologica. 1997;82(5):577-80.

37. Aoki J, Ishiyama K, Taniguchi S, Fukuda T, Ohashi K, Ogawa H, et al. Outcome of allogeneic hematopoietic stem cell transplantation for acute myeloid leukemia patients with central nervous system involvement. Biol Blood Marrow Transplant. 2014;20(12):2029-33.

38. Chang H, Brandwein J, Yi QL, Chun K, Patterson B, Brien B. Extramedullary infiltrates of AML are associated with CD56 expression, 11 q23 abnormalities and inferior clinical outcome. Leuk Res. 2004;28(10):1007-11.

39. Mayadev JS, Douglas JG, Storer BE, Appelbaum FR, Storb R. Impact of cranial irradiation added to intrathecal conditioning in hematopoietic cell 
transplantation in adult acute myeloid leukemia with central nervous system involvement. Int J Radiat Oncol Biol Phys. 2011;80(1):193-8.

40. Morra E, Lazzarino M, Brusamolino E, Pagnucco G, Castagnola C, Bernasconi

$P$, et al. The role of systemic high-dose cytarabine in the treatment of central nervous system leukemia. Clinical results in 46 patients. Cancer. 1993;72(2):439-45.

41. Ghaddar HM, Plunkett W, Kantarjian HM, Pierce S, Freireich EJ, Keating MJ, et al. Long-term results following treatment of newly-diagnosed acute myelogenous leukemia with continuous-infusion high-dose cytosine arabinoside. Leukemia. 1994;8(8):1269-74.

Submit your next manuscript to BioMed Central and take full advantage of:

- Convenient online submission

- Thorough peer review

- No space constraints or color figure charges

- Immediate publication on acceptance

- Inclusion in PubMed, CAS, Scopus and Google Scholar

- Research which is freely available for redistribution 